RICYDE. Revista Internacional de Ciencias del Deporte doi: $10.5232 /$ ricyde

Rev. int. cienc. deporte

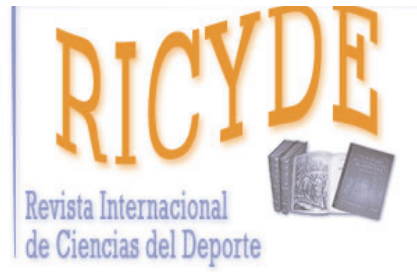

RICYDE. Revista Internacional de Ciencias del Deporte VOLUME XI - YEAR XI

pages:348-359 ISSN:1885-3137

Issue 42 - October - 2015

\title{
Effects of static-stretching and whole-body-vibration during warm-ups on bench-press kinematics in males and females college-aged \\ Efectos de los estiramientos estáticos y vibraciones durante el calentamiento en los parámetros cinemáticos del press banca en hombres y mujeres estudiantes
}

\author{
Esperanza Martín-Santana, Sonsoles Hernández-Sánchez, \\ Azael J. Herrero-Alonso, David García-López \\ European University Miguel de Cervantes, Spain
}

\section{Resumen}

This study aimed to examine the effects of different specific warm-up protocols including static stretching (SS) and whole body vibrations (WBV) on kinematics and number of repetitions during a bench press set to failure in physically active male and female subjects. A secondary purpose was to analyze the role of sex on the warmup induced effects. 24 participants ( 13 females and 11 males) were randomly assigned to complete 3 experimental conditions in a cross-over design: SS, WBV and SS+WBV. After each condition, participants performed one bench-press set to volitional exhaustion with a load equivalent to the $60 \%$ of one-repetition maximum $(1 R M)$. No significant differences $(P>0.05)$ were observed in number of repetitions, mean and maximal accelerative portion (AP), mean and maximal velocity, and lifting velocity time-course pattern. Males showed significantly higher values regarding number of repetitions achieved and maximal and mean lifting velocity. However, regarding the percentage of the concentric phase in which barbell is accelerated, there were no sex differences. In conclusion, no relevant difference in kinematics variables can be shown when applying any of these three different warm-up protocols, these results may be useful when designing training programs. We recommend the protocol SS due to the cost-benefit relationship.

Key words: accelerative portion; muscle power; neuromuscular performance.

\section{Abstract}

El objetivo de este estudio fue examinar el efecto de diferentes protocolos de calentamiento incluyendo estiramientos estáticos (EE) y vibraciones de cuerpo entero (WBV) en variables cinemáticas y número de repeticiones completadas en una serie de press banca realizada hasta el fallo muscular, en hombres y mujeres físicamente activos. Un segundo objetivo fue analizar el papel de la variable sexo en los efectos inducidos por el calentamiento. 24 participantes (13 mujeres y 11 hombres) completaron, de forma aleatoria, 3 condiciones experimentales con un diseño cruzado: EE, WBV, y EE+WBV. Al terminar cada protocolo de calentamiento los sujetos realizaron una serie de press banca al fallo con una carga equivalente al $60 \%$ de una repetición máxima (1RM). No se observaron diferencias significativas entre condiciones experimentales en lo que respecta al número de repeticiones completadas, velocidad media y máxima, porcentaje acelerativo (AP) y evolución de la velocidad a lo largo de la serie. En el grupo de los hombres se observaron unos valores significativamente mayores en el número de repeticiones y velocidad media y máxima en comparación con las mujeres. Sin embargo, cuando se examina los percentiles en los que la barra acelera en la fase concéntrica no existen diferencias significativas entre hombres y mujeres. En conclusión, no existen diferencias significativas relativas a los parámetros cinemáticos o al número de repeticiones completadas cuando se aplican estiramientos estáticos, vibraciones de cuerpo completo o una combinación de ambas estrategias durante el calentamiento, estos resultados pueden ser útiles para el diseño del calentamiento en programas de entrenamiento. Debido a la relación coste-beneficio se puede recomendar el protocolo EE.

Palabras clave: aceleración; potencia muscular; rendimiento neuromuscular.

Correspondencia/correspondence: Esperanza Martín Santana

European University Miguel de Cervantes, Spain

Email: msespe@hotmail.com 
Martín-Santana, E.; Hernández-Sánchez, S.; Herrero-Alonso, A.J., \& García-López, D. (2015). Effects of staticstretching and whole-body-vibration during warm-ups on bench-press kinematics in males and females college-aged. RICYDE. Revista internacional de ciencias del deporte, 42(11), 348-359.

http://dx.doi.org/10.5232/ricyde2015.04204

\section{Introduction}

A lmost all athletes perform warm-up (WU) routines prior to formal training and competition because it is thought that they assist in optimizing performance levels and reducing the relative risk of injury. Thus, the role of a warm-up is to prepare cardiovascular, muscular and neural systems to meet the demands of a specific activity (Hedrick, 1992). Traditionally, pre-participation of warm-ups have included some active aerobic activities (including running, light calisthenics), static stretching exercises (SS) of the major muscle groups and sport-specific movements incorporating various range of motion exercises with skills-based drills executed at, or just below game intensity, but the optimum warm-up cannot be defined with precision (Fradkin, Zazryn, and Smoliga, 2010). In this sense, static stretching (SS) is commonly used as a part of the warm-up in either sport or recreational related facilities, although the literature is not unanimous in reporting effects on performance. For example, various authors have demonstrated that SS has a negative effect on subsequent strength-related performance (Behm and Chaouachi, 2011; Rubini, Costa, and Gomes, 2007; Yamaguchi and Ishii, 2005). In contrast, several studies have not reported any decrease in force nor power production after SS (Egan, Cramer, Massey and Marek, 2006; Molacek, Conley, Evetovich and Hinnerichs, 2010; Torres, Kraemer, Vingren, Volek, Hatfield, Spiering, Ho, Fragala, Thomas, Anderson, Häkkinen, and Maresh 2008; Yapicioglu, Colakoglu, Gulluoglu, Bademkiran, and Ozkaya, 2013).

In the same line, whole body vibration (WBV) has been investigated as part of different warm-up protocols (Jacobs and Burns, 2009; Kinser, Ramsey, O’Bryant, Ayres, Sands, and Stone, 2008). WBV is a mechanical stimulus that enters the human body via feet when standing on a vibration platform. The improvement induced in the subsequent activity may result from recruitment of previously inactive motor units (Mischi and Cardinale, 2009), enhanced motor excitability (Delecluse, Roelants, and Verschueren, 2003), increased muscle temperature (Cochrane, Stannard, Sargeant, and Rittweger, 2008) as well as enhanced neural functions resulting from tonic vibration reflex (Lapole and Perot, 2010), so the use of WBV might be a good option to optimize the effects of the WU on maximal muscular performance. To our knowledge, only a few studies have investigated the effects of a combination of vibration and SS as a part of the warm-up. In this sense, it has been demonstrated that an acute combination of vibration and SS can be a means of increasing range of motion beyond that obtained with SS alone in trained gymnasts (Kinser et al., 2008). On the contrary, this stimuli combination showed no effects on vertical jump performance (Yapicioglu et al., 2013). However, in such studies the vibration was applied directly to the muscle belly or the tendon by a vibration unit (punctual system). Part of the ambiguity related to the acute effects of SS and WBV on force-related performance can be attributed to the much different intensity, frequencies and durations, as well as to the different training status of the participants analyzed in the different studies (Marín, Bunker, Rhea, and Ayllón, 2009; Simic, Sarabon, and Markovic, 2013).

To our knowledge, the effects of a warm-up combining SS and vibration stimuli via feet (WBV) on kinematics of upper-body resistance exercises have not been studied. A better knowledge about the SS and WBV components, which can maximize the benefits of the preparticipation WUs seems to be essential for athletes such as tennis and handball players, as they must perform high-intensity short-term throwing since the beginning until the end of a match where the success may be affected by small margins and match preparation. 
Martín-Santana, E.; Hernández-Sánchez, S.; Herrero-Alonso, A.J., \& García-López, D. (2015). Effects of staticstretching and whole-body-vibration during warm-ups on bench-press kinematics in males and females college-aged. RICYDE. Revista internacional de ciencias del deporte, 42(11), 348-359.

http://dx.doi.org/10.5232/ricyde2015.04204

Kinematics (e.g. velocity and acceleration) has been proposed as one of the most important stimuli for maximal strength and muscle power resistance training-induced adaptations (McDonagh and Davies, 1984). Many studies have investigated kinematics associated to different resistance exercises and loads performed by different training-level participants (García-López, Herrero, Abadía, Garcia-Isla, Uali, and Izquierdo, 2008; García-López, Izquierdo, Rodríguez, González-Calvo, Sáinz,Abadía, and Herrero2010; García-López, Hernández-Sánchez, Martín, Marín, Zarzosa, and Herrero,2014). Hence, the primary purpose of this study was to examine the effects of different specific warm-up protocols including SS and WBV on kinematics (velocity and accelerative portion) and number of repetitions during a bench press set to failure in recreationally trained male and female participants. Following previous literature (Kinser et al, 2008), it was hypothesized than WBV superimposed with SS would provide an additional stimulus for the neuromuscular system, improving acute performance.

Since research has suggested that there are substantial male-female differences on muscular performance (Courtright, McCormick, Postlethwaite, Reeves, and Mount, 2013; Unick, Kieffer, Cheesman, and Feeny, 2005), a secondary purpose of the present study was to analyze the role of sex on the warm-up induced effects. We hypothesized that the different SS and WBV specific warm-up approaches would affect men and women in a similar pattern, even though women would show lower scores concerning kinematic parameters in comparison with men.

\section{Methods}

\section{Research design}

a) Design:

This study was designed to assess the effect of different specific warm-up protocols on the number of repetitions, accelerative portion and lifting velocity of the concentric phase during a bench press set to failure. A hypothetical sex-effect concerning these acute effects was also investigated.

\section{b) Procedures:}

Data collection took place over a period of five weeks with one testing session each week. During the first session, instructions regarding the 1RM testing and proper form and lifting technique for the bench press were given to each participant. Moreover, during this first session, the warm-up protocols were explained and descriptive data were collected. In the second experimental session, 1RM for the bench press was determined. During each of the next 3 testing sessions, one of the three warm-up protocols was performed each day in a random, counterbalanced order followed by one set of the bench press (60\% of 1RM) leading to failure. During all sessions, participants wore the same athletic shoes to standardize the damping of the vibration due to the footwear (Marin et al., 2009). Testing sessions were carried out the same day of the week at the same time of the day to minimize the circadian influence (Cochrane et al., 2008).

\section{Participants}

Twenty four recreationally active college-aged males and females participated in this study (11 male and 13 female). Table 1 shows descriptive specific data for the different groups. Participants were physically active, and all of them averaged at least 3 months of experience with free-weight resistance exercises and training leading to failure. Their normal workouts 
Martín-Santana, E.; Hernández-Sánchez, S.; Herrero-Alonso, A.J., \& García-López, D. (2015). Effects of staticstretching and whole-body-vibration during warm-ups on bench-press kinematics in males and females college-aged. RICYDE. Revista internacional de ciencias del deporte, 42(11), 348-359.

http://dx.doi.org/10.5232/ricyde2015.04204

typically lasted just less than 90 minutes and entailed training of multiple body parts and exercises. However, at the time of the study and from 2 months before, none were engaged in any regular or organized stretching and/or resistance-training program. Moreover, participants did not allow their sleeping, eating, and drinking habits to change throughout study participation. Before any participation, the experimental procedures and potential risks were explained to the participants, and they provided a written informed consent. The research project was conducted according to the Declaration of Helsinki and it was approved by the University Review Board for Use of Human Subjects.

Table 1. Participants ' characteristics. Values are means \pm SD.

\begin{tabular}{|c|c|c|c|c|c|}
\hline Group & $\begin{array}{c}\text { Age } \\
\text { (Years })\end{array}$ & $\begin{array}{c}\text { Weight } \\
(\mathrm{kg})\end{array}$ & $\begin{array}{c}\text { Height } \\
(\mathrm{cm})\end{array}$ & $\begin{array}{c}\text { BMI } \\
\left(\mathrm{kg} / \mathrm{m}^{2}\right)\end{array}$ & $\begin{array}{c}\text { BenchPress } \\
1 \mathrm{RM}\end{array}$ \\
\hline Men & $20.6 \pm 1.4$ & $75.9 \pm 7.8$ & $179.0 \pm 4.8$ & $23.4 \pm 1.3$ & $74.2 \pm 6.5$ \\
\hline Women & $23.7 \pm 3.4$ & $57.7 \pm 12.1$ & $163.4 \pm 5.9$ & $22.6 \pm 4.2$ & $41.9 \pm 7.9$ \\
\hline All & $22.1 \pm 2.9$ & $67.3 \pm 13.2$ & $172.0 \pm 9.5$ & $22.6 \pm 3.0$ & $51.3 \pm 16.6$ \\
\hline
\end{tabular}

Maximal strength measurement

1RM bench press was assessed using a previously established protocol (Stone and O'Bryant, 1987). Briefly, after a light warm-up on the bench press, the participants attempted to lift a load that was increased progressively, and allowing 3 minutes of rest between attempts. 1RM value was obtained using as few attempts as possible (5 attempts maximum). No participant required more than 4 attempts to obtain the 1RM.

\section{Experimental warm-up conditions}

In a random, counterbalanced order, each participant performed a general warm-up followed by one of the three specific warm-up protocols. The general warm-up consisted in 5 minutes of low-resistance cycling on an ergometer (50 watts and 75 watts for females and males, respectively), followed by two sets of 15 repetitions of shoulder and wrist circumduction in both directions. Then, participants performed 2 sets of 15 repetitions of standard push-ups. Immediately after this general warm-up, participants carried out one of the specific protocols:

Static Stretching (SS) - A sequence of 7 stretches (right and left neck lateral flexion, overhead reach, right and left deltoid side press, right and left triceps square, upper back stretch, right and left side bends, and right and left major pectoral stretching) was performed during 4 minutes and 30 seconds, according to a previous study (Torres et al., 2008). Each stretch was held for 20 seconds followed by a 5-second interval before the next exercise. 20 seconds of static stretching was recommended as the most effective duration (Fortier, Lattier, and Babault, 2013; Rubini et al., 2007; Torres et al., 2008). Participants were informed that the holding point of the stretch was established at the point "just before discomfort" (Unick et al., 2005). Stretching was performed on the platform in order to avoid a setting-related bias. Feet spacing was set at shoulder width.

Whole Body Vibration (WBV) - Participants were exposed to WBV at $50 \mathrm{~Hz}$ and 2-mmpeak-to peak $\left(2-\mathrm{mm}_{\mathrm{p}-\mathrm{p}}\right)$ amplitude during 4 minutes and 30 seconds. The WBV condition was carried out with the participants standing with their whole feet on the vibration platform (Power PlatePro5 ${ }^{\circledR}$, Power Plate North America, Northbrook, IL, USA) allowing minimal bend in the knees $\left(170^{\circ}\right.$ knee extension) (Jacobs and Burns, 2009) and both hands were 
Martín-Santana, E.; Hernández-Sánchez, S.; Herrero-Alonso, A.J., \& García-López, D. (2015). Effects of staticstretching and whole-body-vibration during warm-ups on bench-press kinematics in males and females college-aged. RICYDE. Revista internacional de ciencias del deporte, 42(11), 348-359.

http://dx.doi.org/10.5232/ricyde2015.04204

placed on the hips. Feet spacing was shoulder was set at shoulder width.

Static stretching plus whole body vibration (SS+WBV) - Same stretches used in protocol SS plus the same vibratory stimuli applied in the WBV protocol performed at the same time.

During the stretching exercises, the participants were assisted by a researcher.

\section{Bench press test}

The bench press protocol consisted of a bench-press set performed to failure, with a load equivalent to participant's $60 \%$ of 1RM. Thus, 1 minute after the warm-up, participants were asked to move the barbell as fast as possible during the concentric phase of each repetition and the eccentric phase controlled (1-2 seconds), until volitional exhaustion. The participants were not permitted to raise the shoulders off the bench, and no pause was allowed between the eccentric and concentric phases. Lastly, the participants could not "bounce" the barbell off the chest. Failure was defined, according to a previously established criterion (GarcíaLópez et al., 2008; García-López et al., 2010), as the time point when the barbell ceased to move, if the participant stopped more than 1 second when the arms were in the extended position, or if the participant was unable to reach the full extension position of the arms. Kinematics parameters of each repetition were monitored by attaching a transducer to the end of the barbell, which was linked to a rotary encoder (Globus Real Power ${ }^{\circledR}$, Globus, Codogne, Italy). The rotary encoder recorded the position of the barbell with an accuracy of $0.1 \mathrm{~mm}$ and time events with an accuracy of 0.001 seconds. Total repetitions, mean and maximum velocity and accelerative portion for test set and mean velocity for each repetition (during the concentric phase of each repetition) were determined. For comparison purposes, the number of repetitions was expressed as a percentage of the total number of repetitions $(10 \%, 20 \%$, $30 \%, \ldots 100 \%)$.

\section{Statistical Analyses}

Normality of the dependent variables was checked and subsequently confirmed using the Shapiro-Wilk test. Dependent variables were compared in respect to protocol condition (i.e., WBV vs. SS vs. WBV+SS) and sex (i.e. men vs. women) using a mixed two-way analysis of variance with repeated measures. When a significant F-value was achieved, pair wise comparisons were performed using the Bonferroni post hoc procedure. Effect sizes $(d)$ were computed to determine the magnitude of an effect between groups independent of sample size. Values of $d=0.2$ were considered small effects, $0.2<d<0.8$ moderate, and $d>0.8$ large (Thomas, Salazar, and Landers, 1991). Statistical significance was set at $\mathrm{P}=0.05$. Variable values were expressed as mean \pm standard deviations (SD).

\section{Results}

\section{Number of repetitions}

No significant protocol effect was observed regarding the number of repetitions achieved $\left(\mathrm{P}=0.452, \eta^{2}=0.035\right)$ with no protocol-sex interaction $\left(\mathrm{P}=0.696, \eta^{2}=0.016\right)$ (Figure 1). On the contrary, a significant sex effect was observed $(\mathrm{P}=0.002, d=4.67)$. That is, men showed a significantly higher number of repetitions than women after SS $(27.3 \%, \mathrm{P}=0.001, d=1.51)$, WBV $(21.3 \%, \mathrm{P}=0.035, d=0.87)$ and $\mathrm{SS}+\mathrm{WBV}(23.5 \%, \mathrm{P}=0.006, d=1.05)$ protocols, respectively. 
Martín-Santana, E.; Hernández-Sánchez, S.; Herrero-Alonso, A.J., \& García-López, D. (2015). Effects of staticstretching and whole-body-vibration during warm-ups on bench-press kinematics in males and females college-aged. RICYDE. Revista internacional de ciencias del deporte, 42(11), 348-359.

http://dx.doi.org/10.5232/ricyde2015.04204

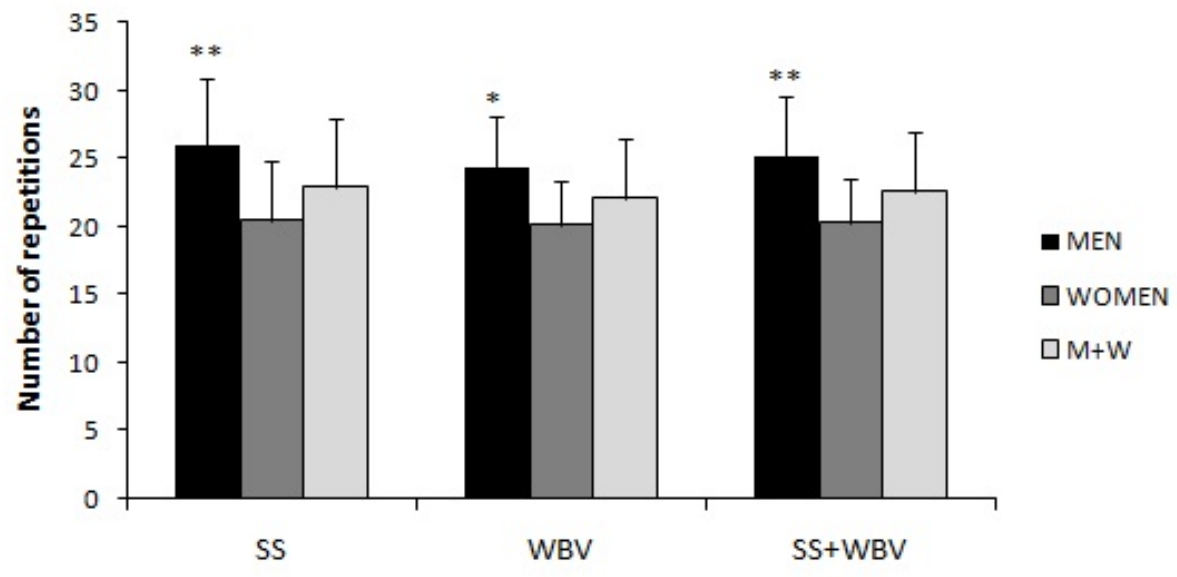

Figure 1. Number of repetitions completed after each warm-up protocol. Values are mean \pm SD. * and ** significantly different from women at $\mathrm{P}<0.05$ and $\mathrm{P}<0.01$, respectively.

\section{Accelerative portion (AP)}

Table 2 shows data concerning average and maximum AP. Regarding average AP there were no protocol $\left(\mathrm{P}=0.307, \eta^{2}=0.052\right)$, sex $(\mathrm{P}=0.873, d=0.22)$ or protocol-sex interaction $(\mathrm{P}=0.185$, $\left.\eta^{2}=0.074\right)$ significant effects. In the same line, no protocol $\left(\mathrm{P}=0.914, \eta^{2}=0.004\right)$, sex $(\mathrm{P}=0.615$, $d=0.69)$ or protocol-sex interaction $\left(\mathrm{P}=0.850, \eta^{2}=0.007\right)$ significant effects were observed concerning maximal AP. During the set, the repetition with the highest AP $(77.2 \%$ of the whole range of motion) corresponded to the second or the third repetition.

Table 2. Bench press testing values. Values are mean $\pm \mathrm{SD}$. ** and $* * *$ different from women, same condition $(\mathrm{P}<0.01$ and $\mathrm{P}<0.001$, respectively).

\begin{tabular}{|c|c|c|c|c|c|c|c|c|c|}
\hline & \multicolumn{3}{|c|}{ SS } & \multicolumn{3}{|c|}{ WBV } & \multicolumn{3}{|c|}{$\mathrm{SS}+\mathrm{WBV}$} \\
\hline & Men & Women & $\mathrm{M}+\mathrm{W}$ & Men & Women & $\mathrm{M}+\mathrm{W}$ & Men & Women & $\mathrm{M}+\mathrm{W}$ \\
\hline $\begin{array}{c}\mathrm{AP}_{\text {mean }} \\
(\%)\end{array}$ & $59.82 \pm 6.23$ & $60.00 \pm 6.01$ & $59.92 \pm 5.97$ & $57.98 \pm 5.99$ & $60.86 \pm 3.28$ & $59.54 \pm 4.83$ & $62.53 \pm 4.62$ & $60.33 \pm 7.37$ & $61.34 \pm 6.24$ \\
\hline $\begin{array}{c}\mathrm{AP}_{\max } \\
(\%)\end{array}$ & $78.02 \pm 3.35$ & $76.98 \pm 3.30$ & $77.46 \pm 3.29$ & $77.50 \pm 3.67$ & $76.98 \pm 3.19$ & $77.22 \pm 3.35$ & $77.64 \pm 2.82$ & $77.34 \pm 4.36$ & $77.48 \pm 3.66$ \\
\hline $\begin{array}{l}V_{\text {mean }} \\
\left(\mathrm{m} \cdot \mathrm{s}^{-1}\right)\end{array}$ & $0.357 \pm 0.107 * *$ & $0.256 \pm 0.042$ & $0.302 \pm 0.092$ & $0.319 \pm 0.038^{* * *}$ & $0.247 \pm 0.045$ & $0.280 \pm 0.055$ & $0.322 \pm 0.039 * *$ & $0.259 \pm 0.041$ & $0.288 \pm 0.050$ \\
\hline $\begin{array}{c}\mathrm{V}_{\max } \\
\left(\mathrm{m} \cdot \mathrm{s}^{-1}\right)\end{array}$ & $0.480 \pm 0.132 * *$ & $0.352 \pm 0.045$ & $0.411 \pm 0.114$ & $0.428 \pm 0.055^{* *}$ & $0.350 \pm 0.061$ & $0.385 \pm 0.070$ & $0.439 \pm 0.061^{* *}$ & $0.360 \pm 0.054$ & $0.396 \pm 0.069$ \\
\hline
\end{tabular}

\section{Lifting velocity}

No significant protocol effect was observed regarding mean and maximum lifting velocity $\left(\mathrm{P}=0.234, \eta^{2}=0.064\right.$ and $\mathrm{P}=0.343, \eta^{2}=0.047$, respectively $)$. On the other hand, a significant sex effect was detected $(\mathrm{P}=0.000$ and $\mathrm{P}=0.000$, respectively) (Table 2$)$. That is, men showed a significantly higher mean velocity after SS $(39.2 \%, \mathrm{P}=0.005, d=0.93)$, WBV $(29.3 \%$, $\mathrm{P}=0.000, d=1.90)$ and $\mathrm{SS}+\mathrm{WBV}(24.2 \%, \mathrm{P}=0.001, d=1.60)$ protocols, respectively. Similar results were observed concerning maximum velocity; that is, men showed significantly higher values after SS $(37.1 \%, \mathrm{P}=0.003, d=0.97)$, WBV $(22.3 \%, \mathrm{P}=0.004, d=1.42)$, and $\mathrm{SS}+\mathrm{WBV}$ $(21.9 \%, \mathrm{P}=0.003, d=1.29)$ protocols, respectively. 
Martín-Santana, E.; Hernández-Sánchez, S.; Herrero-Alonso, A.J., \& García-López, D. (2015). Effects of staticstretching and whole-body-vibration during warm-ups on bench-press kinematics in males and females college-aged. RICYDE. Revista internacional de ciencias del deporte, 42(11), 348-359.

http://dx.doi.org/10.5232/ricyde2015.04204

A significant decrease in average lifting velocity was observed throughout the sets leading to failure, both in men and women (Figures 2 and 3). In men, the repetition at which a significant decrease $(\mathrm{P}<0.05)$ in the initial relative velocity occurred corresponded to $60 \%$ (WBV protocol) and 40\% (SS and SS+WBV protocols) (Figure 2) of total repetitions achieved. In women, the repetition at which a significant decrease $(\mathrm{P}<0.05)$ in the initial relative velocity occurred corresponded to $40 \%$ (SS protocol) and 50\% (WBV and SS+WBV protocols) (Figure 3).

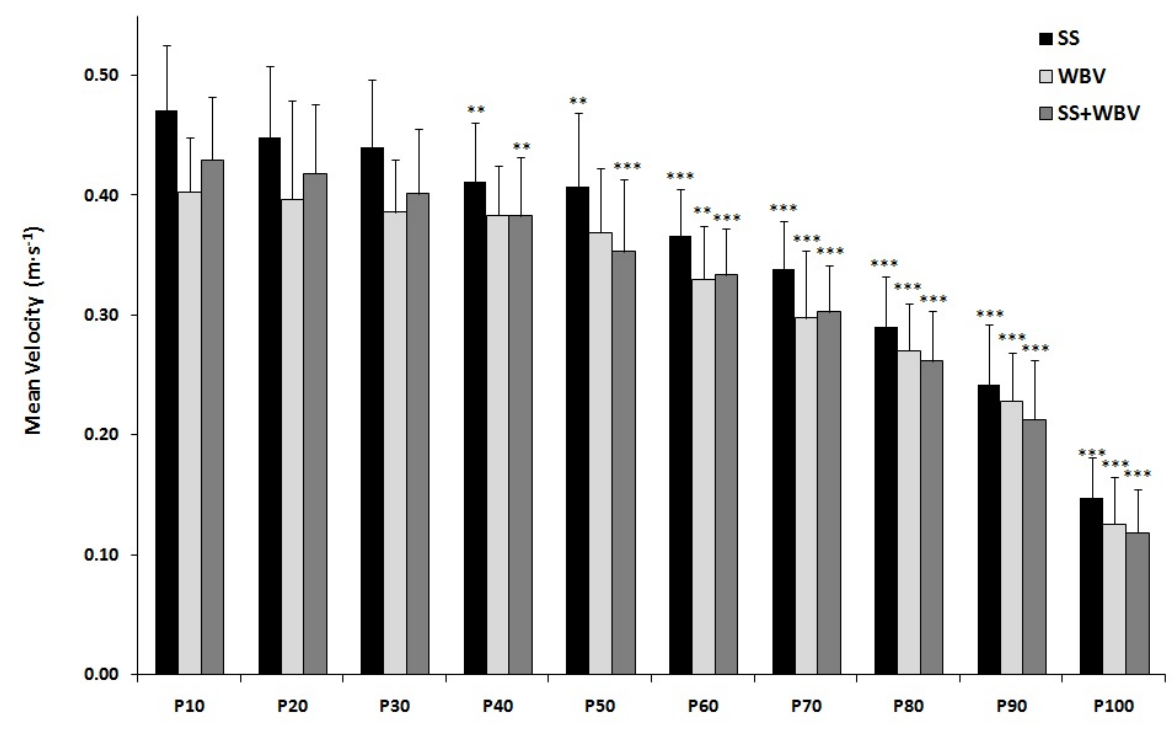

Figure 2. Mean velocity for all warm-up conditions in men. Number of repetitions is expressed as a percentage of total number of repetitions completed. Values are means $\pm \mathrm{SD}$. ** and $* * *$ significantly different from $\mathrm{P} 10$ at $\mathrm{P}<0.01$ and $\mathrm{P}<0.001$, respectively.

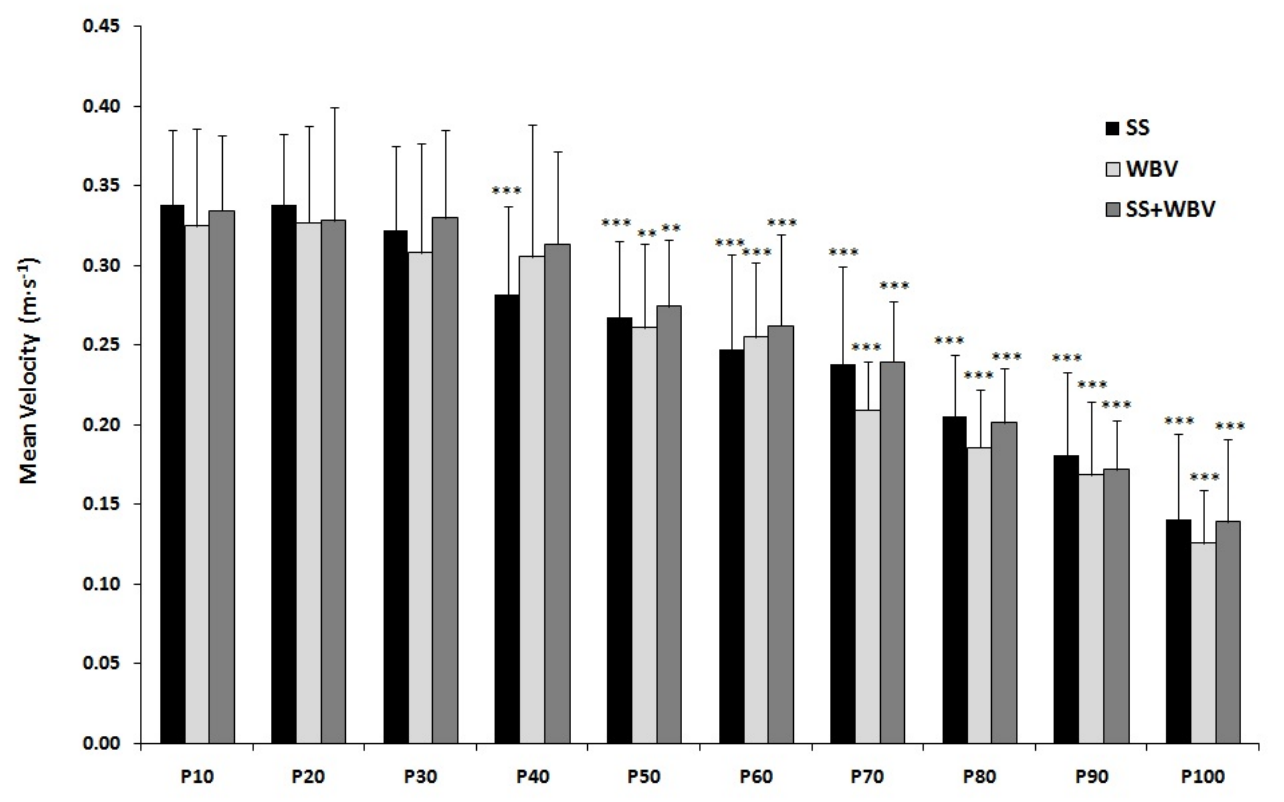

Figure 3. Mean velocity for all warm-up conditions in women. Number of repetitions is expressed as a percentage of total number of repetitions completed. Values are means \pm SD. $* *$ and $* * *$ significantly different from $\mathrm{P} 10$ at $\mathrm{P}<0.01$ and $\mathrm{P}<0.001$, respectively. 
Martín-Santana, E.; Hernández-Sánchez, S.; Herrero-Alonso, A.J., \& García-López, D. (2015). Effects of staticstretching and whole-body-vibration during warm-ups on bench-press kinematics in males and females college-aged. RICYDE. Revista internacional de ciencias del deporte, 42(11), 348-359.

http://dx.doi.org/10.5232/ricyde2015.04204

\section{Discussion}

To the best of our knowledge, this is the first study analyzing the acute effects of different warm-up protocols using SS and WBV on performance and kinematic parameters (i.e. AP and lifting velocity) of the bench press. Moreover, the role of gender over all the dependent variables was investigated. The main finding of the present research was that the use of SS, WBV or a combination of both (SS+WBV) during the warm-up affects in a similar pattern the number of repetitions, the mean and maximal AP, the mean and maximal velocity, and the lifting velocity time-course pattern of the concentric phase during a bench press set to failure.

Negative (Behm and Chaouachi, 2011; Rubini et al., 2007; Yamaguchi and Ishii, 2005) and null (Egan et al., 2006; Molacek, Conley, Evetovich, and Hinnerichs, 2010; Torres et al., 2008; Yapicioglu et al., 2013) effects have been reported after SS. In this sense, in nearly all of the studies that reported significant decreases in maximal strength, the stretching routine was longer and more intense than what most competitive and recreational athletes would do (Beedle, Rytter, Healy, and Ward, 2008). The stretching position is usually held at a point of slight discomfort for 15 to 30 seconds (Torres et al., 2008). In agreement with previous studies, we found that shorter durations of stretching within a warm-up $(<30$ seconds of total stretching duration per muscle) may not affect negatively in subsequent performance. This duration might not be sufficient to alter the viscoelastic properties of the muscles or to lead to acute changes in voluntary muscle activation or reflex sensitivity (Behm and Chaouachi, 2011; Torres et al., 2008).

WBV stimulus causes short and rapid changes in muscle fiber length which result in skeletal muscle reflex contractions (Ritzmann, Kramer, Gruber, Gollhofer, and Taube, 2010), and it has been applied during warm-up protocols in order to improve subsequent performance (Jacobs and Burns, 2009; Kinser et al., 2008). Although different studies have found improvements in performance when WBV is applied simultaneously to resistance training exercises, there is no unanimity when the WBV stimulus is applied prior to exercise. In this sense, different studies have shown that WBV applied in static squat position may improve vertical jump performance for up to 5 minutes post exposure (Armstrong, Grinnell, and Warren, 2010). On the contrary, Marín et al. (2013), who used a vibration magnitude similar to that used in the present research, found that 30 seconds of WBV exposure in squat position induced no effects on power or strength during a set of elbow-extension resistance exercise, performed also 1 minute after the WBV stimuli. Therefore the effect of WBV applied via a ground-based platform on upper body performance could exist, but the window effect seems to be smaller in comparison with lower body exercises. This limited effect could occur due to a decrease in cortical and/or spinal activity due to an inadequate dose of stimulus (Marín et al., 2013). Although no unanimity exists, theories on how vibration affects muscular performance are related to neural factors, specifically the stimulation of Ia afferents by the muscle spindle, which excites homonymous motor neurons (Ferguson, Kim, Seo, and Bemben, 2013).

When considering the combination of stretching and vibration stimuli the results showed by Yapicioglu et al. (2013) are in line with the present study. In such a study, 30 seconds of punctual vibration superimposed to Achilles tendon stretching did not induce any significant change in vertical jump performance. Methodological differences existing between Yapicioglu's study and the present research make difficult to establish direct comparisons. These differences are mainly related to the exercise tested (vertical jump vs. bench press), and the nature of the vibratory stimuli (punctual vibration to the tendon vs. WBV). 
Martín-Santana, E.; Hernández-Sánchez, S.; Herrero-Alonso, A.J., \& García-López, D. (2015). Effects of staticstretching and whole-body-vibration during warm-ups on bench-press kinematics in males and females college-aged. RICYDE. Revista internacional de ciencias del deporte, 42(11), 348-359.

http://dx.doi.org/10.5232/ricyde2015.04204

As it was hypothesized, the effects of the warm-up protocols investigated were similar in men and women. Our results are in accordance with Courtright et al. (2013), whose meta-analysis revealed that males score substantially better on muscular strength tests. In the present study, males showed significantly higher values in 1RM, number of repetitions achieved and maximal and mean lifting velocity. However, regarding the percentage of the concentric phase in which barbell is accelerated (AP), there were no sex differences. Specific literature reports accelerative portions ranging from $60 \%$ to $66 \%$ in Smith machine bench press for loads equivalent to $45 \%$ to $60 \%$ of 1RM (García-López et al., 2008; García-López et al., 2010). In the present study, in which bench press was performed in a free-weight approach, the maximal AP was approximately the $77 \%$ of the concentric range of motion. The deceleration phase is inherent to the lift, and occurs even though there is an attempt to increase or maintain movement speed, particularly when using light resistances and trying to lift them quickly. We have recently demonstrated that large deceleration phases, which are undesirable when attempting to maximize power performance, can be reduced through the use of superimposed elastic resistance (García-López et al., 2014). To the best of our knowledge, this is the first study showing that an important kinematic variable, such as AP, is not sex dependent, even though other strength related variables, like velocity and muscular endurance, are usually higher in men than in women. In the same line, there were no sex differences concerning the lifting velocity time-course pattern of the concentric phase during the set to failure. That is, over a set of repetitions until failure the speed of the concentric phase slows natural and similarly in men and women, being this decrease significant when the number of repetitions was over one half of the total number of repetitions performed, which is in line with previous studies (García-López et al., 2008).

In summary, the use of WBV, SS or a combination of both (SS+WBV) during the warm-up affects in a similar pattern the number of repetitions, the mean and maximal AP, the mean and maximal velocity, and the lifting velocity time-course pattern of the concentric phase during a bench press set to failure performed with a load equivalent to the $60 \%$ of $1 \mathrm{RM}$. Although men can achieve a higher number of repetitions, and these repetitions are performed at a higher speed, sex differences concerning AP and lifting velocity time-course pattern are inexistent. Future research should test different SS and WBV protocols (i.e. concerning duration, intensity) in order to reinforce the present data.

\section{Practical applications}

Stretching and whole body vibrations applied before participation in sport activities is a common practice among athletes, coaches and recreational exercisers. The present study points out similar acute effects of these warm-up techniques, applied alone or in a combined approach, on different performance and kinematic parameters. Based on these results, we cannot recommend the use of WBV during all the warm-up periods, since it requires special tools and the effects over some kinematic aspects are not relevant. Coaches have to decide in each situation depending on the individual purpose. Although previous research has suggested that there are substantial male-female differences on muscular performance, this study has demonstrated that women and men can accelerate the barbell during a similar percentage of the concentric range of motion, even though men shows higher velocity values. Moreover, lifting velocity declines pattern of the concentric phase throughout a set to failure is not sex-dependent. Since kinematics associated to resistance exercises (e.g. velocity and acceleration) have been proposed as one of the most important stimuli for maximal strength and muscle power resistance training-induced adaptations, these results may be useful when designing training programs. Future research may analyze different stretching parameters (i.e. 
Martín-Santana, E.; Hernández-Sánchez, S.; Herrero-Alonso, A.J., \& García-López, D. (2015). Effects of staticstretching and whole-body-vibration during warm-ups on bench-press kinematics in males and females college-aged. RICYDE. Revista internacional de ciencias del deporte, 42(11), 348-359.

http://dx.doi.org/10.5232/ricyde2015.04204

stretching time) or WBV parameters (i.e. amplitude, frequency) in order to reinforce the current data.

\section{References}

Armstrong, W.J.; Grinnell, D.C., \& Warren, G.S. (2010). The acute effect of whole-body vibration on the vertical jump height. Journal of Strength and Conditioning Research, 24(10), 2835-2839.

http://dx.doi.org/10.1519/JSC.0b013e3181e271cc

Beedle, B.; Rytter, S.J.; Healy, R.C., \& Ward, T.R. (2008). Pretesting static and dynamic stretching does not affect maximal strength. Journal of Strength and Conditioning Research, 22(6), 1838-1843.

http://dx.doi.org/10.1519/JSC.0b013e3181821bc9

Behm, D.G., \& Chaouachi, A. (2011). A review of the acute effects of static and dynamic stretching on performance. European Journal of Applied Physiology, 111(11), 26332651.

http://dx.doi.org/10.1007/s00421-011-1879-2

Cochrane, D.J.; Stannard, S.R.; Sargeant, A.J., \& Rittweger, J. (2008). The rate of muscle temperature increase during acute whole-body vibration exercise. European Journal of Applied Physiology, 103(4), 441-448.

http://dx.doi.org/10.1007/s00421-008-0736-4

Courtright, S.H.; McCormick, B.W.; Postlethwaite, B.E.; Reeves, C.J., \& Mount, M.K. (2013). A meta-analysis of sex differences in physical ability: Revised estimates and strategies for reducing differences in selection contexts. Journal of Applied Psychology, 98(4), 623-641.

http://dx.doi.org/10.1037/a0033144

Delecluse, C.; Roelants, M., \& Verschueren, S. (2003). Strength increase after whole body vibration compared with resistance training. Medicine \& Science in Sports \& Exercise, 35(6), 1033-1041.

http://dx.doi.org/10.1249/01.MSS.0000069752.96438.B0

Egan, A.D.; Cramer, J.T.; Massey, L.L., \& Marek, S.M. (2006). Acute effects of static stretching on peak torque and mean power output in National Collegiate Athletic Association Division I women's basketball players. Journal of Strength and Conditioning Research, 20(4), 778-782.

http://dx.doi.org/10.1519/r-18575.1

Ferguson, S.L.; Kim, E.; Seo, D., \& Bemben, M.G. (2013). Comparing the effects of 3 weeks of upper-body vibration training, vibration and stretching, and stretching alone on shoulder flexibility in college-aged men. Journal of Strength and Conditioning Research, 27(12), 3329-3334.

http://dx.doi.org/10.1519/JSC.0b013e31828f27af

Fortier, J.; Lattier, G., \& Babault, N. (2013). Acute effects of short-duration isolated static stretching or combined with dynamic exercises on strength, jump and sprint performance. Science \& Sports, 28, 111-117.

http://dx.doi.org/10.1016/j.scispo.2012.11.003

Fradkin, A.J.; Zazryn, T.R., \& Smoliga, J.M. (2010). Effects of warming-up on physical performance: a systematic review with meta-analysis. Journal of Strength and Conditioning Research, 24(1), 140-148.

http://dx.doi.org/10.1519/JSC.0b013e3181c643a0 
Martín-Santana, E.; Hernández-Sánchez, S.; Herrero-Alonso, A.J., \& García-López, D. (2015). Effects of staticstretching and whole-body-vibration during warm-ups on bench-press kinematics in males and females college-aged. RICYDE. Revista internacional de ciencias del deporte, 42(11), 348-359.

http://dx.doi.org/10.5232/ricyde2015.04204

García-López, D.; Hernández-Sánchez, S.; Martín, E.; Marín, P.J.; Zarzosa, F., \& Herrero, J.A. (in press). Free-weight augmentation with elastic bands improves bench-press kinematics in professional rugby players. Journal of Strength and Conditioning Research.

http://dx.doi.org/10.1519/jsc.0000000000000374

García-López, D.; Herrero, J.A.; Abadía, O.; Garcia-Isla, F.J.; Uali, I., \& Izquierdo, M. (2008). The role of resting duration in the kinematic pattern of two consecutive bench-press sets to failure in elite sprint kayakers. International Journal of Sports Medicine, 29(9), 764-769.

http://dx.doi.org/10.1055/s-2008-1038376

García-López, D.; Izquierdo, M.; Rodríguez, S.; González-Calvo, G.; Sáinz, N.; Abadía, O., \& Herrero, J.A. (2010). Inter-set stretching does not influence kinematic profile of consecutive bench-press sets. Journal of Strength and Conditioning Research, 24(5), 1361-1368.

http://dx.doi.org/10.1519/JSC.0b013e3181cf780d

Hedrick, A. (1992). Physiological responses to warm-up. Journal of Strength and Conditioning Research, 14(5), 25-27.

http://dx.doi.org/10.1519/0744-0049(1992)014<0025:PRTWU>2.3.CO;2

Jacobs, P.L., \& Burns, P. (2009). Acute enhancement of lower-extremity dynamic strength and flexibility with whole-body vibration. Journal of Strength and Conditioning Research, 23(1), 51-57.

http://dx.doi.org/10.1519/JSC.0b013e3181839f19

Kinser, A.M.; Ramsey, M.W.; O'Bryant, H.S.; Ayres, C.A.; Sands, W.A., \& Stone, M.H. (2008). Vibration and stretching effects on flexibility and explosive strength in young gymnasts. Medicine \& Science in Sports \& Exercise, 40(1), 133-140. http://dx.doi.org/10.1249/mss.0b013e3181586b13

Lapole, T., \& Perot, C. (2010). Effects of repeated Achilles tendon vibration on triceps surae force production. Journal of Electromyography and Kinesiology, 20(4), 648654.

http://dx.doi.org/10.1016/j.jelekin.2010.02.001

Marín, P.J.; Bunker, D.; Rhea, M.R., \& Ayllón, F.N. (2009). Neuromuscular activity during whole-body vibration of different amplitudes and footwear conditions: implications for prescription of vibratory stimulation. Journal of Strength and Conditioning Research, 23(8), 2311-2316. http://dx.doi.org/10.1519/JSC.0b013e3181b8d637

Marín, P.J.; Herrero, A.J.; Milton, J.G.; Hazell, T.J., \& García-López, D. (2013). Wholebody vibration applied during upper body exercise improves performance. Journal of Strength and Conditioning Research, 27(7), 1807-1812. http://dx.doi.org/10.1519/JSC.0b013e3182772f00

Marín, P.J.; Herrero, A.J.; Sáinz, N.; Rhea, M.R., \& García-López, D. (2010). Effects of different magnitudes of whole-body vibration on arm muscular performance. Journal of Strength and Conditioning Research, 24(9), 2506-2511.

http://dx.doi.org/10.1519/JSC.0b013e3181e38188

McDonagh, M.J., \& Davies, C.T. (1984). Adaptive response of mammalian skeletal muscle to exercise with high loads. European Journal of Applied Physiology and Occupational Physiology, 52(2), 139-155. http://dx.doi.org/10.1007/BF00433384

Mischi, M., \& Cardinale, M. (2009). The effects of a $28-\mathrm{Hz}$ vibration on arm muscle activity during isometric exercise. Medicine \& Science in Sports \& Exercise, 41(3), 
Martín-Santana, E.; Hernández-Sánchez, S.; Herrero-Alonso, A.J., \& García-López, D. (2015). Effects of staticstretching and whole-body-vibration during warm-ups on bench-press kinematics in males and females college-aged. RICYDE. Revista internacional de ciencias del deporte, 42(11), 348-359.

http://dx.doi.org/10.5232/ricyde2015.04204

645-653.

http://dx.doi.org/10.1249/MSS.0b013e31818a8a69

Molacek, Z.D.; Conley, D.S.; Evetovich, T.K., \& Hinnerichs, K.R. (2010). Effects of lowand high-volume stretching on bench press performance in collegiate football players. Journal of Strength and Conditioning Research, 24(3), 711-716. http://dx.doi.org/10.1519/JSC.0b013e3181c7c242

Ritzmann, R.; Kramer, A.; Gruber, M.; Gollhofer, A., \& Taube, W. (2010). EMG activity during whole body vibration: motion artifacts or stretch reflexes? European Journal of Applied Physiology, 110(1), 143-151.

http://dx.doi.org/10.1007/s00421-010-1483-x

Ronnestad, B.R. (2009). Acute effects of various whole-body vibration frequencies on lower-body power in trained and untrained subjects. Journal of Strength and Conditioning Research, 23(4), 1309-1315.

http://dx.doi.org/10.1519/JSC.0b013e318199d720

Rubini, E.C.; Costa, A.L., \& Gomes, P.S. (2007). The effects of stretching on strength performance. Sports Medicine, 37(3), 213-224. http://dx.doi.org/10.2165/00007256-200737030-00003

Simic, L., Sarabon, N., \& Markovic, G. (2013). Does pre-exercise static stretching inhibit maximal muscular performance? A meta-analytical review. Scandinavian Journal of Medicine \& Science in Sports, 23(2), 131-148. http://dx.doi.org/10.1111/j.1600-0838.2012.01444.x

Stone, M., \& O'Bryant, E. (1987). Weight Training. A Scientific Approach. Minneapolis, MN: Burgess.

Thomas, J.R.; Salazar, W., \&Landers, D.M. (1991). What is missing in $p<.05$ ? Effect size. Research Quarterly for Exercise and Sport, 62(3), 344-348. http://dx.doi.org/10.1080/02701367.1991.10608733

Torres, E.M.; Kraemer, W.J.; Vingren, J.L.; Volek, J.S.; Hatfield, D.L.; Spiering, B.A.; Ho, J.Y.; Fragala, M.S.; Thomas, G.A.; Anderson, J.M.; Häkkinen, K., \& Maresh, C.M. (2008). Effects of stretching on upper-body muscular performance. Journal of Strength and Conditioning Research, 22(4), 1279-1285. http://dx.doi.org/10.1519/JSC.0b013e31816eb501

Unick, J.; Kieffer, H.S.; Cheesman, W., \& Feeney, A. (2005). The acute effects of static and ballistic stretching on vertical jump performance in trained women. Journal of Strength and Conditioning Research, 19(1), 206-212.

Yamaguchi, T., \& Ishii, K. (2005). Effects of static stretching for 30 seconds and dynamic stretching on leg extension power. Journal of Strength and Conditioning Research, 19(3), 677-683.

Yapicioglu, B., Colakoglu, M., Colakoglu, Z., Gulluoglu, H., Bademkiran, F., \& Ozkaya, O. (2013). Effects of a Dynamic Warm-Up, Static Stretching or Static Stretching with Tendon Vibration on Vertical Jump Performance and EMG Responses. Journal of Human Kinetics, 39(4), 49-57.

http://dx.doi.org/10.2478/hukin-2013-0067 